\title{
Inhibition of radiation induced migration of human head and neck squamous cell carcinoma cells by blocking of EGF receptor pathways
}

\author{
Anja C Pickhard ${ }^{1 *}$, Johanna Margraf ${ }^{1}$, Andreas Knopf $^{1}$, Thomas Stark1', Guido Piontek1', Carolin Beck1,
} Anne-Laure Boulesteix ${ }^{3}$, Elias Q Scherer ${ }^{1}$, Steffi Pigorsch ${ }^{4}$, Jürgen Schlegel ${ }^{2}$, Wolfgang Arnold ${ }^{1}$ and Rudolf Reiter ${ }^{5}$

\begin{abstract}
Background: Recently it has been shown that radiation induces migration of glioma cells and facilitates a further spread of tumor cells locally and systemically. The aim of this study was to evaluate whether radiotherapy induces migration in head and neck squamous cell carcinoma (HNSCC). A further aim was to investigate the effects of blocking the epidermal growth factor receptor (EGFR) and its downstream pathways (Raf/MEK/ERK, PI3K/Akt) on tumor cell migration in vitro.
\end{abstract}

Methods: Migration of tumor cells was assessed via a wound healing assay and proliferation by a MTT colorimeritric assay using 3 HNSCC cell lines (BHY, CAL-27, HN). The cells were treated with increasing doses of irradiation (2 Gy, 5 Gy, 8 Gy) in the presence or absence of EGF, EGFR-antagonist (AG1478) or inhibitors of the downstream pathways PI3K (LY294002), mTOR (rapamycin) and MEK1 (PD98059). Biochemical activation of EGFR and the downstream markers Akt and ERK were examined by Western blot analysis.

Results: In absence of stimulation or inhibition, increasing doses of irradiation induced a dose-dependent enhancement of migrating cells ( $p<0.05$ for the 3 HNSCC cell lines) and a decrease of cell proliferation ( $p<0.05$ for the 3 HNSCC cell lines). The inhibition of EGFR or the downstream pathways reduced cell migration significantly (almost all $p<0.05$ for the 3 HNSCC cell lines). Stimulation of HNSCC cells with EGF caused a significant increase in migration ( $p<0.05$ for the 3 HNSCC cell lines). After irradiation alone a pronounced activation of EGFR was observed by Western blot analysis.

Conclusion: Our results demonstrate that the EGFR is involved in radiation induced migration of HNSCC cells. Therefore EGFR or the downstream pathways might be a target for the treatment of HNSCC to improve the efficacy of radiotherapy.

\section{Background}

Head and neck squamous cell carcinoma (HNSCC) is the sixth most common cancer worldwide [1]. In case of a primary radiotherapy patients get no surgery. Therefore radiation doses need to be higher than in those cases where the patient gets surgery and a postoperative adjuvant radiotherapy.

Anti-neoplastic properties of ionizing radiation are primarily related to DNA damage. This treatment is an

\footnotetext{
* Correspondence: a.pickhard@lrz.tum.de

'Department of Otolaryngology Head and Neck Surgery, Technical University of Munich, Ismaninger Straße 22, 81675 Munich, Germany

Full list of author information is available at the end of the article
}

established measure for HNSCC therapy [2,3]. Despite technological advances and increased radiation intensity only approximately half of the patients get cured [4]. The outcome of patients presenting more advanced stages is even poorer, with 5 -year actuarial survival rates of about 30\% [5]. These findings underscore the need to develop novel strategies in the management of patient with advanced HNSCC.

In the last decade significant progress has been made in the understanding of the molecular mechanisms that are responsible for human cancer development and progression. The epidermal growth factor receptor (EGFR), a member of the structurally related erbB family of

\section{Biomed Central}


tyrosine kinase receptors, has been implicated in cancer development and progression in a large number of tumors including HNSCC [6]. EGFR over-expression occurs early in the pathogenesis of HNSCC [7] and is associated with reduced relapse-free survival or poor overall survival time [8]. Also a new study shows, that EGFR protein levels strongly predict for patient outcome in HNSCC [9]. At a clinical level, inhibition of EGFR with monoclonal antibody showed therapeutic effects with better survival of patients when added to standard radiotherapy [10]. In advanced or metastatic tumors cetuximab plus chemotherapy had significant effects compared with chemotherapy alone on outcome of overall survival and progression-free survival [11].

Interestingly, in a glioma cell model it has been shown that sublethal irradiation promotes migration and invasion of tumor cells [12].

It has been shown on a molecular level that radiation induces an overexpression of EGFRs in many HNSCC $[7,13,14]$. Cassell et al. mentioned that inhibition of EGFR with a monoclonal antibody (cetuximab, Erbitux ${ }^{\mathrm{TM}}$ ), enhanced the development of more effective HNSCC treatments. But there is a need of a prospective identification of patients who would benefit from such a therapy [15]. Besides, a phase III randomised trial has shown that the combination of radiotherapy with the EGFR antibody cetuximab significantly improves overall survival at 5 years [16].

Molecular research has identified a host of new biological parameters with potential predictive utility. Oncogenes, tumor suppressor genes, cell-cycle control genes, apoptosis genes and angiogenesis genes have been extensively studied and correlated with radiation response $[17,18]$.

Akt (protein kinase b) as a possible response modulator has recently fostered molecular strategies which employ blockade of the receptor to down-regulate tumor growth [19]. Besides, inhibition of Rhokinase or PI3 kinase decreases tumor growth and cisplatin resistance in HNSCC [20]. Also, expression levels of phosphorylated Akt and mTOR are higher in HNSCC than in non-cancer patients [21].

The PI3K dependent pathway and the ERK pathway are important pathways for tumor biology [22]. Raf/ MEK/ERK connect mitogen signals [23], whereas the PI3K dependent activation of the Akt seems to be important for anti-apoptosis and migration [24,25] (Figure 1).

The purpose of our study was twofold: (1) to investigate radiation induced migration of the well established HNSSC cell lines (BHY, CAL-27 and HN) and (2) to investigate the possibility of inhibiting migration by blocking the EGF receptor pathways.

\section{Methods}

\section{Cell culture and irradiation}

The cell lines HN, BHY [26] and CAL-27 [27] were used (DSMZ, Braunschweig, Germany). Cells were grown in Dulbecco's modified Eagle medium (DMEM) or Roswell park memorial institute medium (RPMI 1640) (Invitrogen, Karlsruhe, Germany) containing 10\% fetal calf serum, $2 \mathrm{mM}$ glutamine, and $100 \mu \mathrm{g} / \mathrm{ml}$ penicillin/streptomycin and maintained at $37^{\circ} \mathrm{C}$ in an atmosphere of $5 \% \mathrm{CO}_{2}$ grown to a $70-90 \%$ confluence.

Irradiation was performed at the Department of Radiotherapy (Technical University of Munich). Cells were X-irradiated with single doses of 2, 5 or 8 Gy with a Philips RT 100 (Philips, Amsterdam) operated at 300 $\mathrm{kV}$ with $1.4 \mathrm{~mm}$ copper half-value layer at a dose rate of approximately $1 \mathrm{~Gy} / \mathrm{min}$. The dose inhomogeneity was $\pm 2 \%$. The sham-treated group (0 Gy, control) was subjected to the same protocol as exposed cells.

\section{Wound healing assay}

Investigation of cell migration capability after irradiation treatment was performed by a modified wound healing assay, as described before [28]: Briefly, treated and untreated cells were grown to confluent monolayers. Immediately before irradiation the inhibitors rapamycin (100 nM) (Biomol, Hamburg, Germany), LY294002 (50 $\mu \mathrm{M})$ (Calbiochem, Darmstadt, Germany), PD98059 (50 $\mu \mathrm{M})$ (Biomol, Hamburg, Germany), tyrphostin AG1478 $(10 \mu \mathrm{M})$ (Merck, Darmstadt, Germany) or the epidermal growth factor (EGF) (10 ng/ml) (Upstate, Billerica, USA) were separately added to the medium. After that, the monolayers were wounded by scratching the surface as uniformly as possible with a $200 \mu$ l pipette tip (Sarstedt AG \& Co., Nümbrecht, Germany). After irradiation cells were cultivated for another $12 \mathrm{hrs}$. This initial wounding $(0 \mathrm{hr})$ and the movement of the cells in the scratched area were photographically monitored under an inverted light microscope (field of view by a 40 fold magnification - Axiovert 25, Carl Zeiss AG, Göttingen, Germany, equipped with an Olympus SC 35 Camera, Volketswil, Switzerland). Migrating cells were counted 12 hours after irradiation (Figure 2). These time points were chosen because in former experiments all cells were grown to confluence after 36 hours (data not shown).

\section{Modified Boyden chamber}

To confirm the results of the scratch test we analyzed the migration by a modified Boyden chamber. Cells were given to a transwell permeable polycarbonate membrane with a pore size of $0.8 \mu \mathrm{m}$ (Corning Incorporated, New York, USA). Inhibitors were added in the medium above and under the membrane then irradiation were done. $12 \mathrm{hrs}$ later cells above the membrane 


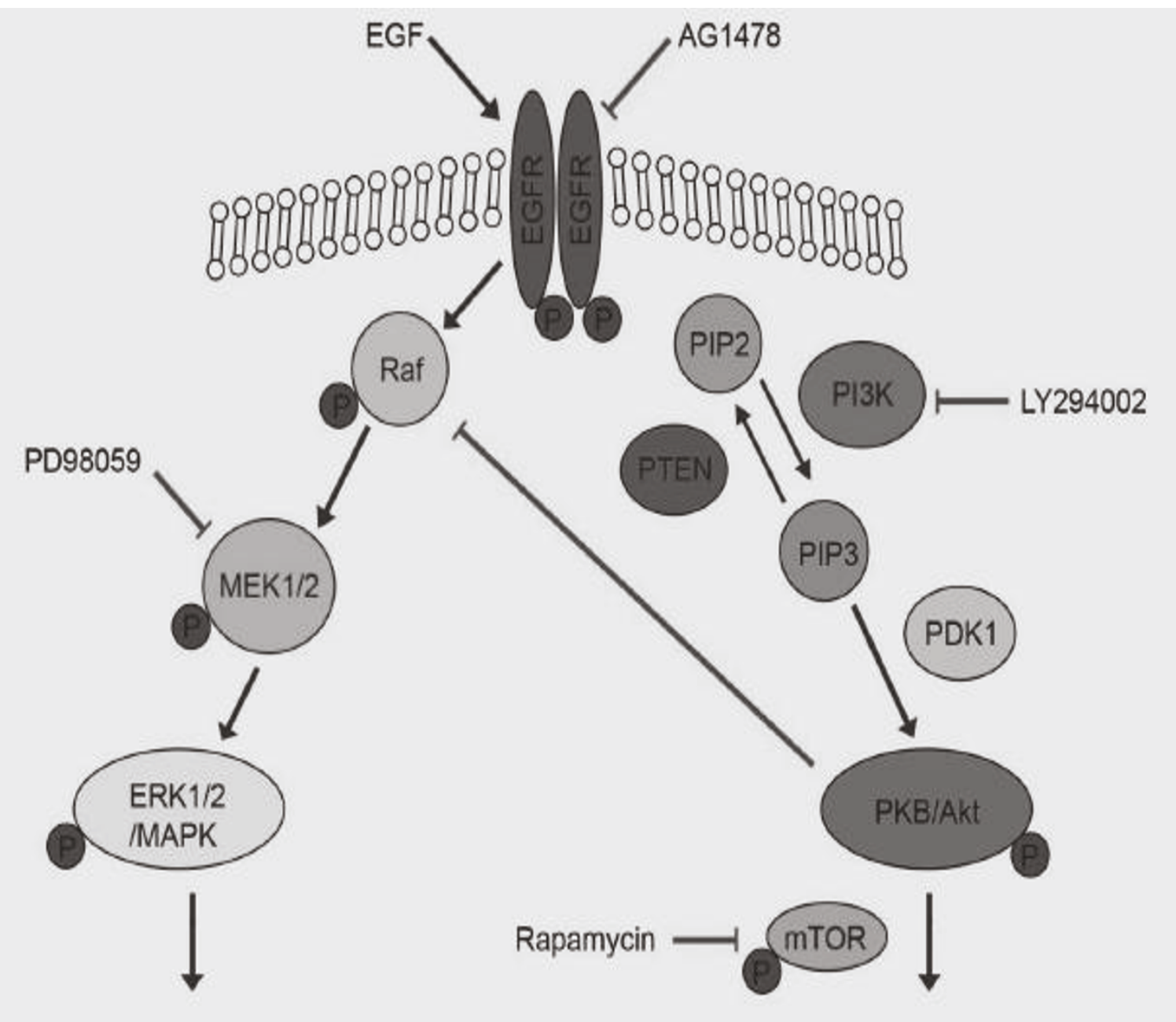

Figure 1 Components of the EGFR pathways and their specific inhibitors. EGFR (Epidermal growth factor receptor), PIP2, PIP3 (Phosphatidylinositol-4,5-bisphosphate (PIP2), Phosphatidylinositol 3,4,5-trisphosphate (PIP3), MAPK/ERK (mitogen activited proteinkinase), mTOR/ FRAP (Mammalian target of rapamycin), PI3K (Phosphatidylinositol-3'-Kinase), PKB/Akt (Proteinkinase B), PTEN (Phosphatase and tensin homologue deleted on chromosome ten).

were removed by a cotton drill, and fixed with DAPI. Thereafter cells were counted under a microscope. These experiments were performed to show consistent and comparable results of radiation induced migration.

\section{Proliferation assessment}

The MTT [3-(4,5-dimethylthiazol-2-yl)-2,5-diphenyltetrazolium bromide] assay (Roche Diagnostics, Penzberg, Germany) was used to assess cell proliferation, as previously described [29]. Briefly, cells were plated on 96well plates at a concentration of 1000 cells/well. The above-mentioned inhibitors were added 12 hours prior to irradiation. After incubation, and 12, 24 and 72 hours after irradiation, $10 \mu \mathrm{l}$ of MTT solution was added to each well for four hours $\left(37^{\circ} \mathrm{C}\right)$. Subsequently, $100 \mu \mathrm{l}$ of dimethylsulfoxide was added to each well, yielding purple solution. The optical density was measured at $590 \mathrm{~nm}$ using an ELISA reader (ASYS Hitech, Eugendorf, Germany) and ratios in relation to controls were made. All experiments were performed eight times $(\mathrm{n}=$ 8).

\section{Immunoblot analysis}

Immunoblot analysis was performed to determine EGFR expression including its downstream proteins ERK and Akt. 12 hours after irradiation, cells were harvested in lysis buffer (Cell Lysis Buffer, New England Biolabs, Ipswich, USA) at $4^{\circ} \mathrm{C}$. Lysates were centrifuged (10000 $\mathrm{rpm}$ ) for 15 minutes at $4^{\circ} \mathrm{C}$ to remove insoluble components. Protein content was quantified by the Bio-Rad Dc protein assay (Bio Rad, Hercules, USA). Equal amounts of protein were separated on SDS-PAGE $10 \%$ or $12.5 \%$ 


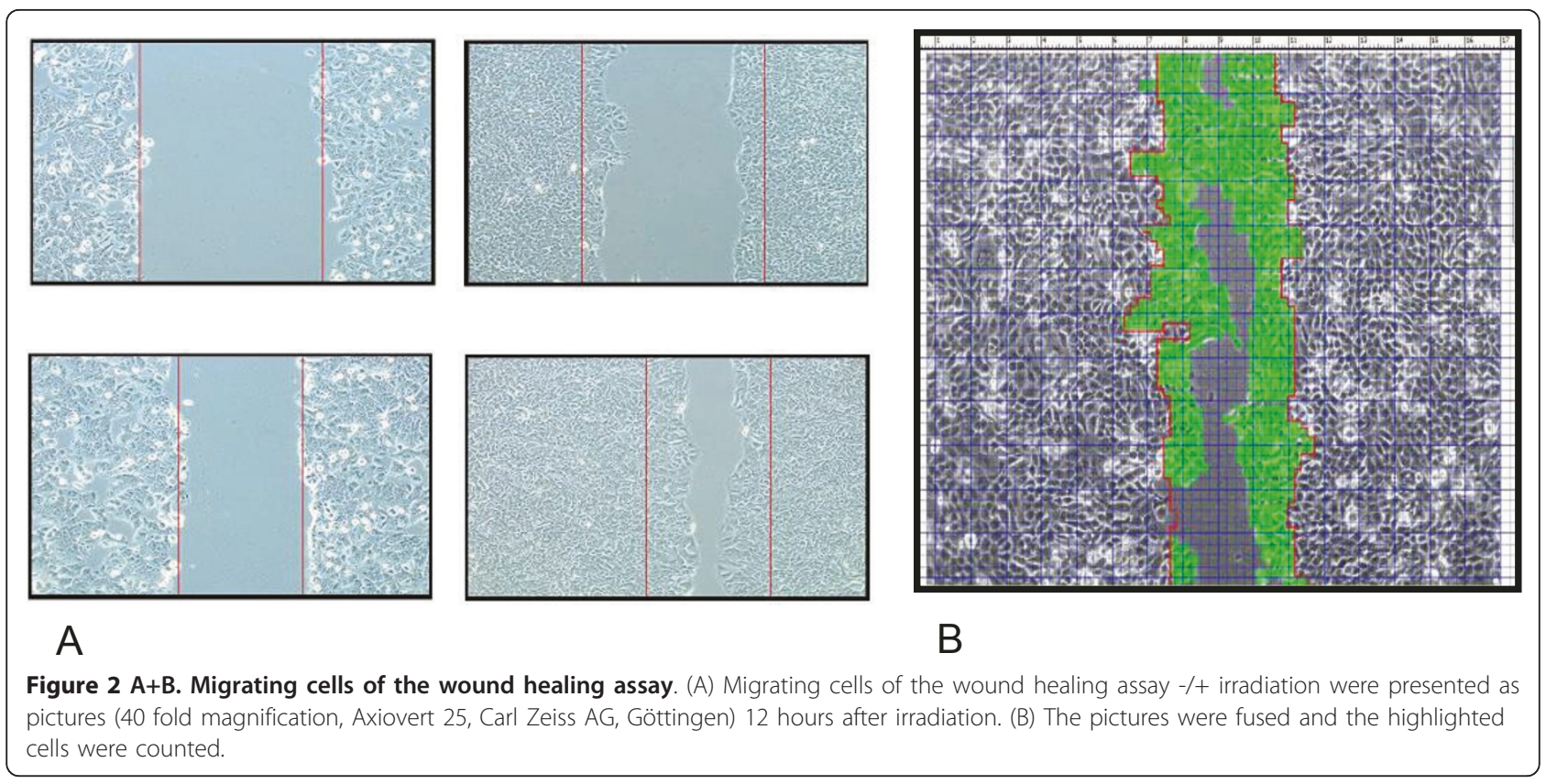

gels. Proteins were transferred to Immobilon-P PVDF membrane (Millipore, Billerica, USA). The membranes were blocked with $5 \%$ nonfat dry milk in Tris-buffered saline containing 0,1\% Tween 20 (TBST) and afterwards incubated with primary antibody in 5\% nonfat dry milk in TBST, followed by secondary antibody linked to rabbitradish peroxidase diluted in 5\% nonfat dry milk in TBST. ECL Detection System for Western blot Analysis (Amersham, Freiburg, Germany) was used according to the manufacturer's instructions. The Imager SRX-101 (Konica Minolta, Langenhagen, Germany) was used to detect bands of appropriate sizes. The following antibodies were used: phospho-EGFR (Tyr1068), phospho-Akt (Ser473), PKB/Akt, phospho-p44/42 ERK (Thr202/ Tyr204), p44/42 ERK, phospho-Raf (Ser259), phosphoMEK1/2, and MEK1/2. All antibodies were obtained from Cell Signaling Technology, (Boston, USA) and used at a dilution of 1:1000.

\section{Data and statistical analysis}

For the investigation of cell migration, a two-factorial design was considered with the factors "treatment" (control, EGF, LY294002, PD98059, rapamycin, AG1478) and radiation dose (ranging from 0 Gy to 8 Gy). The whole analysis was repeated $n=9$ times. Cell proliferation was investigated for all six treatments, for doses 0 Gy and 8 Gy only. For each dose and each group, the sample size was $n=8$. In the whole study, the cells were randomly assigned to the treatment groups and radiation doses.

Radiation induced migration was assessed in a linear regression model were migration was set as dependent variable and the radiation dose as the metric predictor. The potential dose dependent inhibition or enhancement of migration through stimulation was investigated based on a generalized least squares model fitted with the $\mathrm{R}$ function 'gls' with the migration as dependent variable. The predictors were: the radiation dose (metric predictor, coefficient $\beta_{\mathrm{rad}}$ ), the treatment (categorical predictor with coefficients $\beta_{\mathrm{EGF}}, \beta_{\mathrm{AG}}$, etc and controls as reference category), and their interactions (coefficients $\beta_{\text {rad.EGF }}, \beta_{\text {rad.AG }}$, etc). A uniform correlation structure was assumed within each of the $n=9$ experiments, corresponding to a linear mixed model with a random forest for each experiment. Residual analysis showed that this model can reasonably be applied to the data at hand. Additionally, linear hypotheses tests were performed in the above GLS model to test the effect of the radiation dose in the presence of treatment (tested hypotheses: $\beta_{\text {rad }}+\beta_{\text {rad.EGF }}=0, \beta_{\text {rad }}+\beta_{\text {rad.AG }}=0$, etc ). Confidence intervals for the estimated coefficients were calculated, and all hypotheses were tested based on the Wald test. Separate analyses were conducted for the three cell lines BHY, CAL-27 and HN for the time point 12 hours. The t-test was used to compare proliferation in two conditions. Confidence intervals for the difference of means were calculated. All statistical analyses were performed using the R statistical software http:// www.r-project.org, version 2.6.1.

\section{Results}

Blocking of EGFR decreased radiation induced migration The cultured cell lines BHY, CAL-27 and HN were irradiated with 2, 5 and 8 Gy and monitored during 12 


\section{Migrating cells Control}
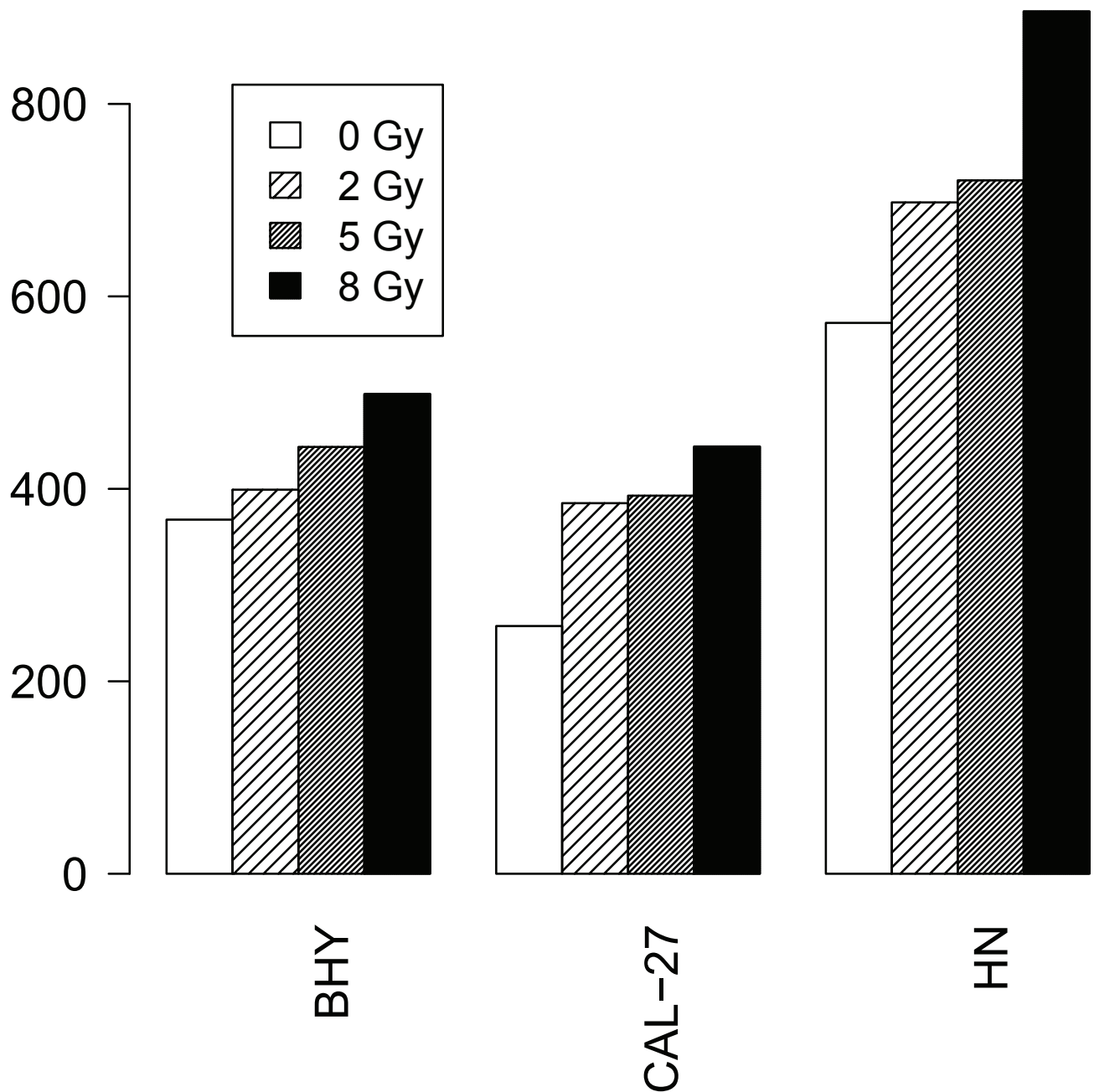

Figure 3 Radiation induced migration. The number of migrating cells after irradiation with 0, 2, 5, and 8 Gy were determined by the wound healing assay for the HNSCC cell lines BHY, CAL-27 and HN. Cells were grown to confluent monolayers, wounded by scratching the surface as uniformly as possible with a pipette tip and afterwards irradiated. The number of migrated tumor cells in the wound was determined. The means and standard errors of 9 tests per time point and dose were calculated after 12 hrs. An increased time dependent migration of tumor cells after irradiation was observed after treatment compared to the control group of not irradiated cells $(p<0.009)$.

hours. The means and standard errors of nine tests per time point and dose were calculated for each cell line. Radiation induced a significant dose dependent migration of tumor cells after irradiation compared to the control group (BHY: $\beta_{\mathrm{rad}}=16, \mathrm{CI}:[6 ; 26], \mathrm{p}=0.003$, CAL-27: $\beta_{\text {rad }}=20$, CI:[10;30], $\mathrm{p}<0.001, \mathrm{HN}: \beta_{\mathrm{rad}}=37$, CI:[22;51], $\mathrm{p}<0.001$ ) (Figure 3).

The findings of the wound healing assay were consistent with the results of the modified Boyden chamber where a radiation induced migration was also observed.
The stimulation of not irradiated (0 Gy) cells with EGF lead to a significant increase of migration in all cell lines (tested hypothesis $\beta_{\mathrm{EGF}}=0$, BHY: $\beta_{\mathrm{EGF}}=137 \mathrm{CI}:[66 ; 209]$, $\mathrm{p}$ $<0.001$, CAL-27: $\beta_{\mathrm{EGF}}=79$, CI:[1;156], $\mathrm{p}=0.048, \mathrm{HN}: \beta_{\mathrm{EGF}}$ $=211, \mathrm{CI}:[113 ; 308], \mathrm{p}<0.001)$. In contrast, the EGFR inhibitor AG1478 significantly decreased migration (Figure 4).

The radiation-induced increase of migration was significantly less pronounced after stimulation with EGF (tested hypothesis $\beta_{\text {rad.EGF }}=0$, BHY: $\beta_{\text {rad.EGF }}=-26$, CI: [-41;-11], p < 0.001, CAL-27: $\beta_{\text {rad.EGF }}=-26$, CI:[-42,-10], $\left.\mathrm{p}=0.002, \mathrm{HN}: \beta_{\text {rad.EGF }}=-21, \mathrm{CI}:[-41,-1 ;], \mathrm{p}=0.042\right)$ as 


\section{BHY - 12 hours \\ Migrating cells}

$$
\left.\begin{array}{r}
600 \\
500 \\
400- \\
300- \\
200 \\
100- \\
0
\end{array}\right]
$$

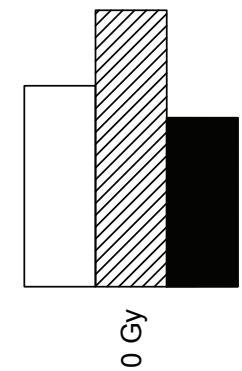

$\left.\begin{array}{r}1200 \\ 1000 \\ 800 \\ 600 \\ 400 \\ 200 \\ 0\end{array}\right]$

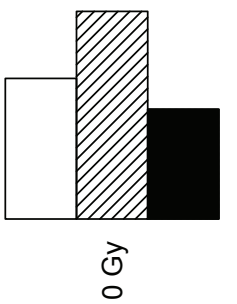

$\left.\begin{array}{r}600 \\ 500- \\ 400 \\ 300- \\ 200- \\ 100- \\ 0\end{array}\right]$

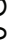

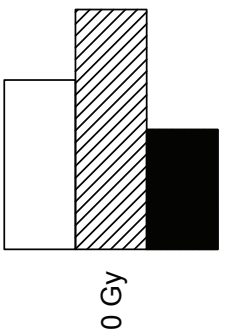

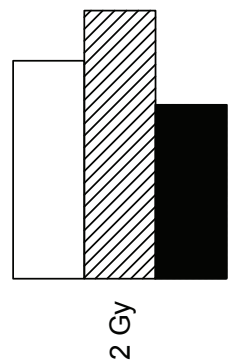

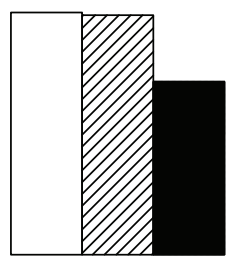

인

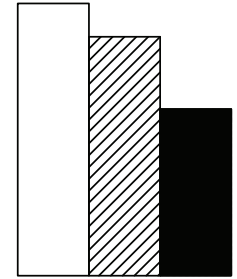

$\underset{\infty}{\text { তे }}$ $\square$ control

ए EGF

AG1478

\section{CAL-27 - 12 hours}

Migrating cells

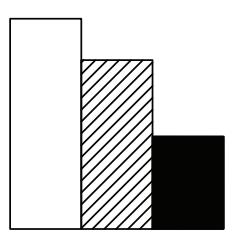

ते

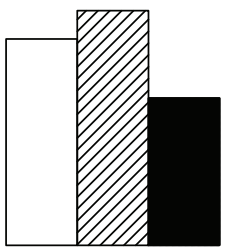

은

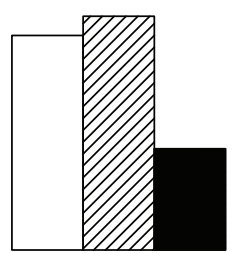

ठे

HN - 12 hours

Migrating cells

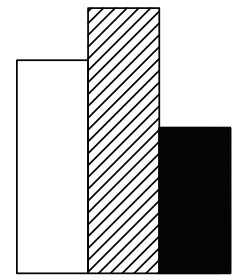

인

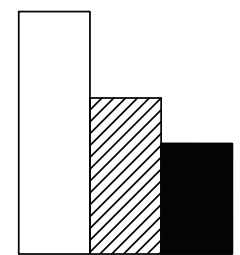

ऽ) $\square$ control

『 EGF

AG1478

Figure 4 AG1478 inhibits radiation induced migration. Migration ability of the 3 different HNSCC cell lines after stimulation with EGF and blocking of the EGFR with AG1478 was determined by the wound healing assay. The means of 9 tests per dosage were calculated after 12 hrs. The increase of migration with increasing radiation dosis was significantly less pronounced after stimulation with EGF and after blocking of EGFR with AG1478 than in control cells.

well as after inhibition with AG1478 (tested hypothesis $\beta_{\text {rad.AG }}=0$, BHY: $\beta_{\text {rad.AG }}=-17$, CI:[-32;-2], $\mathrm{p}=0.028$, CAL-27: $\beta_{\text {rad.AG }}=-19, \mathrm{CI}:[-35 ;-3], \mathrm{p}=0.021, \mathrm{HN}: \beta_{\text {rad. }}$ $\mathrm{AG}=-31, \mathrm{CI}:[-52,-11], \mathrm{p}=0.003)$ than in control cells (Figure 3). More precisely, migration did not increase significantly with radiation dose in the cells stimulated with EGF or inhibited with AG1478 (tested hypotheses: $\left.\beta_{\mathrm{rad}}+\beta_{\text {rad.EGF }}=0, \beta_{\mathrm{rad}}+\beta_{\text {rad.AG }}=0, \mathrm{p}>0.05\right)$, in contrast to what happens in control cells.

Radiation-induced migration can be blocked by inhibition of EGFR downstream pathways

Additionally to the above mentioned inhibition of the EGF receptor, we blocked the downstream pathways of 
EGFR: PI3K by LY294002 (30 minutes before radiation), mTOR by rapamycin (1 hour before radiation) and MEK1 by PD98059 (30 minutes before radiation). A significant negative interaction between irradiation and the inhibitors was seen in the HN cell line after 12 hours. These findings indicate that the radiation-induced migration of tumor cells was decreased significantly by downstream inhibitors of the EGFR (Table 1). Migration was most effectively decreased by blocking of PI3K (LY294002) (Figure 5, Table 1).

After inhibition migration did not significantly increase with radiation dose (tested hypotheses: $\beta_{\text {rad }}$ $+\beta_{\text {rad.LY }}=0, \beta_{\mathrm{rad}}+\beta_{\text {rad.Rapa }}=0, \beta_{\mathrm{rad}}+\beta_{\mathrm{rad} . \mathrm{PD}}=0, \mathrm{p}>$ $0.05)$ in all 3 cell lines, in contrast to what happens in controls. Thus, inhibition seems to attenuate the influence of radiation on migration.

\section{Proliferation subsided by inhibition of the PI3K/Akt pathway}

The strongest migration ability was observed at the dose of $8 \mathrm{~Gy}$. Therefore we focused on studying the effects elicited at this radiation dose. We found a significant decrease of proliferation after radiation with 8 Gy after 72 hours (BHY: CI:[-0.19,-0.12], p < 0.001; CAL-27: CI: [-0.13,-0.05], p < 0.001; HN: CI:[-0.07,-0.01], p = 0.014). Stimulation with EGF showed no significant effect on proliferation (BHY: CI:[-0.11,0.06], $\mathrm{p}=0.5$; CAL-27: $\mathrm{CI}$ : $[-0.09,-0.01], \mathrm{p}=0.02 ; \mathrm{HN}: \mathrm{CI}:[0.02,0.09], \mathrm{p}=0.005)$ without radiation, and no significant effect by simultaneously radiation with 8 Gy (BHY: CI:[-0.06,0.10], p = 0.57; CAL-27: CI:[-0.05,0.01], p = 0.19; HN: CI: $[-0.05,0.005], \mathrm{p}=0.10)$. After EGF receptor blockade with AG1478 a significant decrease in proliferation was observed, compared to the control group (BHY: CI: [-0.27,-0.15],, CAL-27: CI:[-0.20,-0.14],, HN: CI:[-0.13,0.07], $\mathrm{p}<0.001)$.

Inhibition of MEK1 with PD98059 or inhibition of mTOR with rapamycin reduced significantly proliferation (BHY: CI:[-0.25,-0.12], CAL-27: CI:[-0.17,-0.10], HN: CI:[-0.15,-0.07], $\mathrm{p}<0.001)$. Blocking of PI3K with LY294002 also reduced proliferation (BHY: CI:[-0.36,0.31], CAL-27: CI:[-0.26,-0.20], HN: CI:[-0.24,-0.18], p < 0.001) (Figure 6).
EGFR activation after irradiation was detected by Western blot analysis

Protein was isolated at 0 hours and 24 hours after radiation with $8 \mathrm{~Gy}$. In all 3 cell lines we found a constitutive activation of Akt and ERK. The stimulation with EGF preceded an up-regulation of EGFR phosphorylation and a phosphorylation of the downstream pathways. Blockade of the EGFR by AG1478 provoked a down regulation of the receptor, the PI3K/Akt and the Raf/MEK/ ERK pathways. This effect continued during 24 hours. After radiation an up regulation of the EGFR phosphorylation was observed. The western blot results are presented in Figure 7.

\section{Discussion}

Survival rates of HNSCC patients have not improved during the last decades [1]. HNSCC cells distinguish through infiltrative growth in the surrounded area. This is the reason for locally advanced disease in over $40 \%$ of patients [30]. Often tumor location does not allow an in sano resection without severe impairment in functions like swallowing, speech or respiration. Therefore primary radiation therapy is an established therapy of inoperable HNSCC, but the prognosis is poor with five-year-cure rates rarely exceeding $50 \%$ $[4,31]$. Additionally, radiation combined with chemotherapy has been shown to be superior to radiotherapy alone. There are benefits in terms of survival and organ preservation [5]. Also new strategies like the combined-treatment with cisplatin and hyperfractionated radiation therapy maintained improved rates of locoregional control, distant metastasis-free survival, and cancer-specific survival [32]. But unfortunately, no criteria for response to the radiation therapy have been found.

In this study we could demonstrate for the first time a radiation induced migration of HNSCC cells like it is known for glioma cells $[12,33]$. Proliferating cells could make a misleading result in the wound healing assay, because they appear to imitate migration. However, this effect is not caused by proliferating cells, because it was shown in the MTT test that cell proliferation decreases, when cells are irradiated.

Table 1 p-values

\begin{tabular}{lllllllllllll}
\hline time [hrs] & \multicolumn{10}{c}{$1 \mathbf{0}$} & \multicolumn{1}{c}{$\mathbf{2 4}$} \\
\hline treatment & LY & PD & RA & LY+ & PD+ & RA+ & LY & PD & RA & LY+ & PD+ & RA+ \\
\hline BHY & $<0.001$ & 0.781 & 0.050 & 0.089 & 0.023 & 0.021 & $<0.001$ & 0.007 & 0.011 & 0.131 & 0.125 & 0.005 \\
\hline CAL & 0.001 & $<0.001$ & 0.003 & 0.027 & 0.107 & 0.088 & $<0.001$ & $<0.001$ & $<0.001$ & 0.154 & 0.301 & 0.024 \\
\hline HN & $<0.001$ & $<0.001$ & $<0.001$ & 0.002 & 0.041 & 0.014 & $<0.001$ & $<0.001$ & $<0.001$ & 0.001 & 0.003 & $<0.001$ \\
\hline
\end{tabular}

The $p$-values are shown for the effect of blocking in controls (tested hypotheses: $\beta_{\mathrm{LY}}=0, \beta_{\mathrm{PD}}=0, \beta_{\mathrm{RA}}=0$ ) and for the interaction ( + ) with radiation (tested hypotheses: $\beta_{\text {rad.LY }}=0, \beta_{\text {rad.PD }}=0, \beta_{\text {rad.RA }}=0$, etc). All interaction coefficients were negative, indicating that the effect of radiation on migration was weaker after inhibition. (LY294002 (LY), PD98059 (PD), rapamycin (RA)) 


\section{BHY - 12 hours \\ Migrating cells}

$\left.\begin{array}{r}600 \\ 500- \\ 400- \\ 300- \\ 200- \\ 100- \\ 0\end{array}\right]$

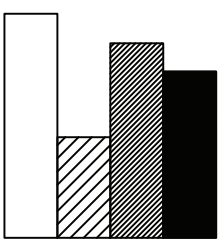

उे

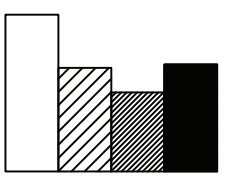

उิ

$\left.\begin{array}{r}1200 \\ 1000 \\ 800 \\ 600- \\ 400- \\ 200- \\ 0\end{array}\right]$

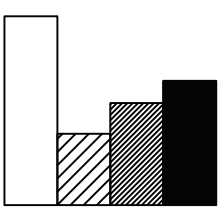

उิ

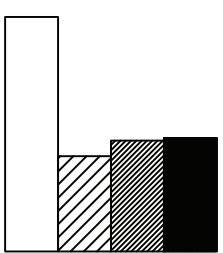

ते

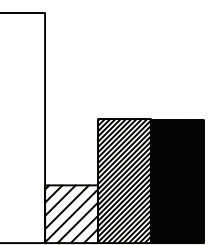

जे

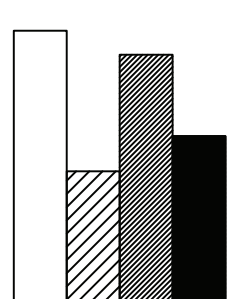

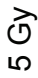

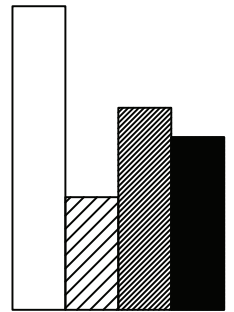

उे

CAL-27 - 12 hrs

Migrating cells

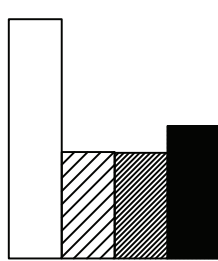

उे

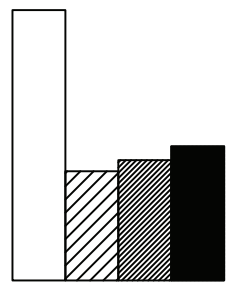

उे

HN - 12 hrs

Migrating cells

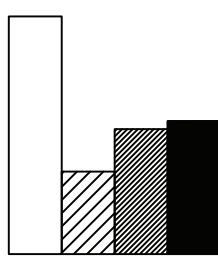

ते

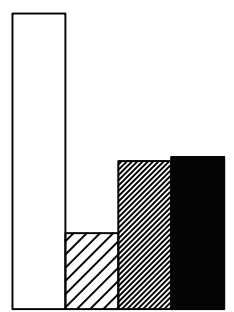

ते

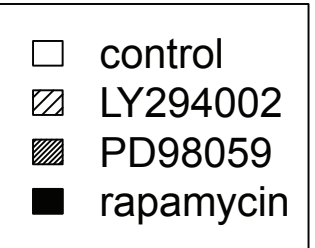

Figure 5 Migration ability of the HNSCC cell lines after blocking of the downstream pathways of the EGFR: PI3K by LY294002 (LY), mTOR by rapamycin (RA) and MEK1 by PD98059 (PD) after irradiation with 0, 2, 5 and 8 Gy after 12 hours. Measurements were made in 9 experiments. The effect of radiation on migration was significantly reduced by inhibitors of the downstream pathways of EGFR. (A cell line BHY, B cell line CAL-27, C cell line HN)

Our results showed that migration is increased by stimulation of the cells with EGF and by radiation treatment. The mechanism might be a radiation induced an autophosphorylation of the EGF receptor with an activation of the downstream pathways, previously observed [14,34]. Blockade of the EGFR by AG1478 that leads to a significant inhibition of migration might support this observation. 


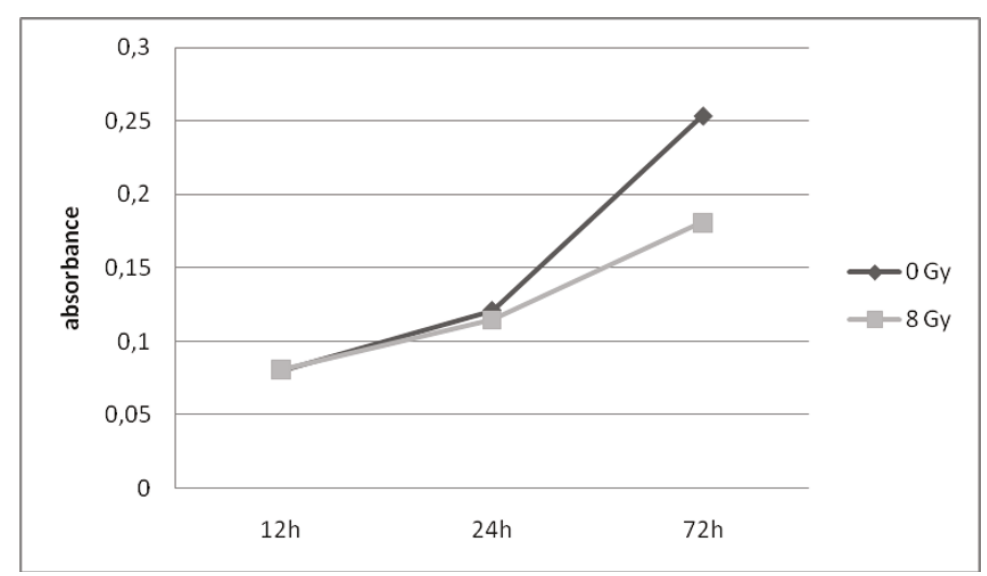

A

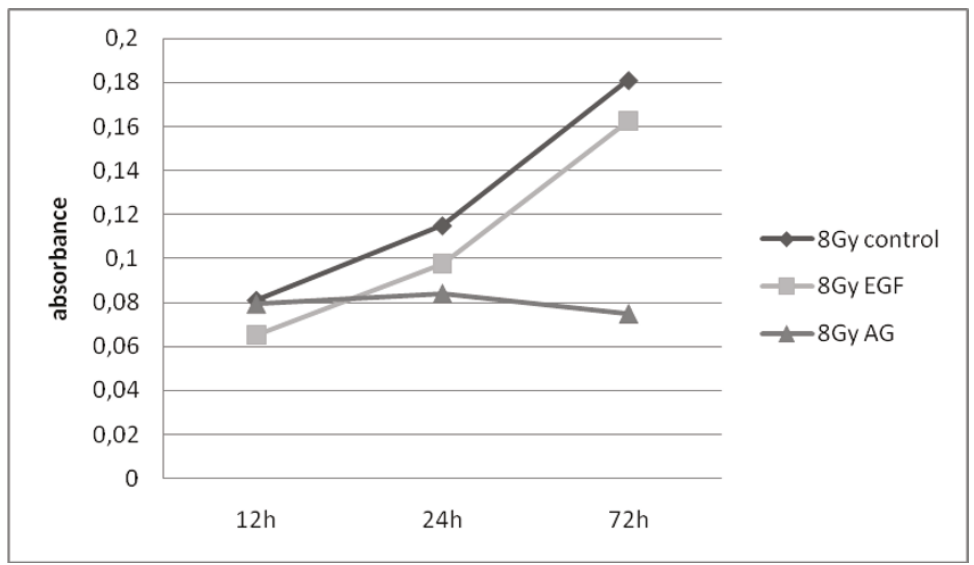

B

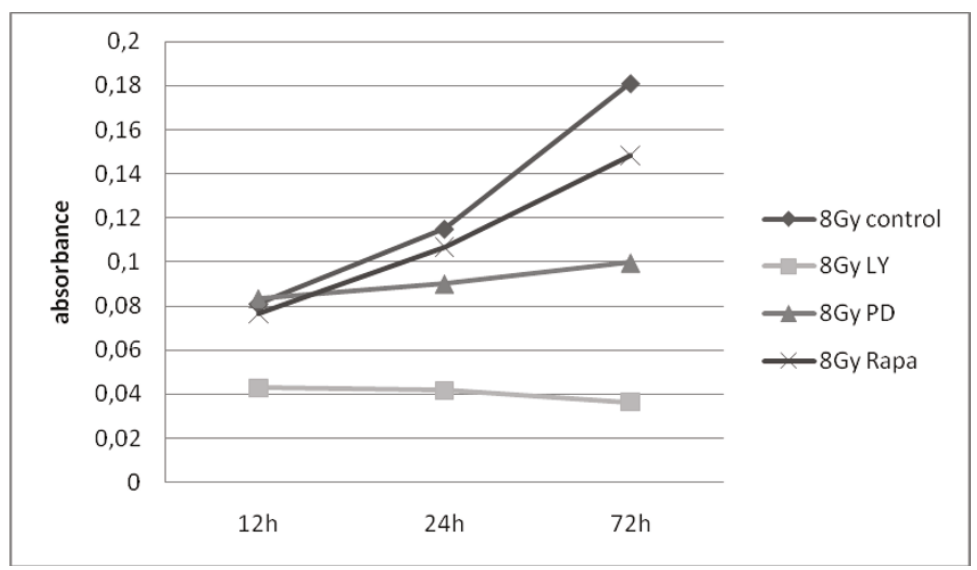

C

Figure $6 \mathrm{~A}+\mathrm{B}+\mathrm{C}$. Subsided proliferation after inhibition. Proliferation was assessed by the MTT test 12 hrs, 24 hrs and 72 hrs after irradiation with 8 Gy or without irradiation ( 0 Gy). Proliferation subsided by radiation of the cell line CAL-27 and also by inhibition of the EGFR by AG1478 (AG) and after blocking of the downstream pathways of the EGFR: PI3K by LY294002 (LY), mTOR by rapamycin (Rapa) and MEK1 by PD98059 (PD), control.

The EGFR plays an important role in tumor biology of HNSCC. In a systematic review, the EGFR signaling is associated with poor prognosis and response to therapy in cervical cancer patients primarily treated with chemoradiation [35]. Bonner et al. showed that the combination of radiotherapy and cetuximab improved the overall survival significantly [16]. Also Frampton found in the setting of locally advanced, unresectable disease, 


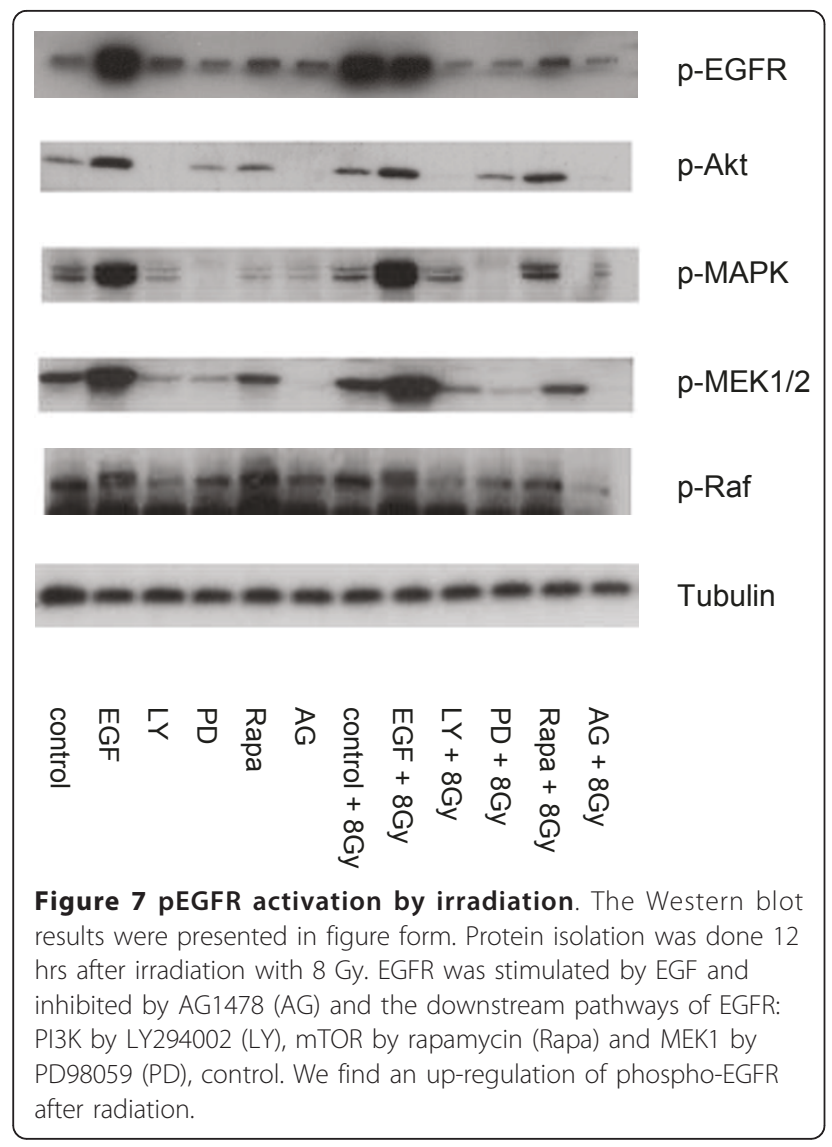

cetuximab plus radiation offers an alternative approach to the current standard of care, namely platinum-based chemotherapy plus radiotherapy and in recurrent and metastatic HNSCC, cetuximab plus platinum-based chemotherapy provides a first-line treatment of choice [36]. The reason for this might be a reduction in cell migration after blocking the EGFR in combination with radiation, as we observed. Recent studies give an account of Akt induced migration $[37,38]$. Therefore we focused on the EGFR downstream pathways Raf/MEK/ERK and PI3K/Akt and investigated whether a correlation with the radiation-induced migration existed. A relation between the PI3K/Akt signaling pathway and the migration was assumed, because inhibition of PI3K by LY294002 and blockade of $\mathrm{mTOR}$ by rapamycin involved a significant decrease of migrating cells. The same effect was seen after inhibition of MEK1 by PD98059. This was confirmed by our western blot results: after radiation we observed an up-regulation of phospho-EGFR, like described in a previous study [14].

The observed constitutive activation of Akt in our HNSCC cell lines was recently confirmed by Bussink et al. [39]. Additionally, clinical trials have shown a strong and independent association between activated Akt expression and treatment outcome [39]. Immediately after inhibition of the PI3K, we saw a down regulation of phospho-Akt, phospho-MEK and phospho-ERK on protein level, whereas phospho-MEK1/2 and phosphoERK were up regulated through the lapse of the Akt dependent phosphorylation of Raf1 on Ser259 after 24 hours as shown by Zimmermann et al. [40].

Actually, the therapy of patients with HNSCC in the advanced stage III and IV implies primary radiotherapy in combination with a chemotherapy [5] and altered fractionation radiotherapy has a benefit for patient survival [31]. Our data indicate that a change in the therapeutic strategies of patients with HNSCC might be useful. Inhibition of the EGFR and/or downstream pathways in combination with the radiotherapy might be an option to the conventional radiation and chemotherapy of patients with HNSCC. In an animal model of nude mice it was shown, that the inhibition of the PI3K by LY294002 in combination with radiation induced a significantly better outcome [41]. Also in human studies involving HNSCC patients treated with a combination of radiation and EGFR antagonization an overall survival benefit was observed in $10 \%-15 \%$ of treated patients [42].

\section{Conclusion}

Our results demonstrate that the EGFR and the downstream signals like PI3K/Akt and Raf/MEK/ERK are involved in radiation induced migration of HNSCC cells and might be a future target for the therapy of HNSCC in combination with radiotherapy.

\section{Author details}

1Department of Otolaryngology Head and Neck Surgery, Technical University of Munich, Ismaninger Straße 22, 81675 Munich, Germany. ${ }^{2}$ Institute of Pathology, Section of Neuropathology, Technical University of Munich, Ismaninger Straße 22, 81675 Munich, Germany. ${ }^{3}$ Institute for Statistics, Ludwig-Maximilians-University Munich, Ludwigstraße 33, 80539 Munich, Germany. ${ }^{4}$ Department of Radiotherapy, Technical University of Munich, Ismaninger Straße 22, 81675 Munich, Germany. ${ }^{5}$ Department of Otolaryngology Head and Neck Surgery, Section of Phoniatrics and Pedaudiology, University of Ulm, Prittwitzstr. 43, 89070 UIm, Germany.

\section{Authors' contributions}

AP conceived of the study, performed the experiments, analysed the results and drafted the manuscript. JM carried out the irradiation experiments, the wound healing assay, the MTT assay and the immunoblot analysis. AK participated in the immunoblot analysis. TS participated in the wound healing assay. GP carried out and participated in the MTT assay, the immunoblot analysis and the modified boyden chamber assay. CB carried out the modified boyden chamber assay. ALB participated in the design of the study and performed the statistical analysis. EQS participated in the MTT assay. SP participated in the irradiation experiments. JS participated in the study design and the achievement of the assays. WA participated in the discussion of the results. RR conceived of the study, and participated in its design and coordination. All authors read and approved the final manuscript.

\section{Competing interests}

The authors declare that they have no competing interests.

Received: 22 January 2010 Accepted: 6 September 2011 Published: 6 September 2011 
References

1. Hunter KD, Parkinson EK, Harrison PR: Opinion - Profiling early head and neck cancer. Nature Reviews Cancer 2005, 5:127-135.

2. Kao J, Lavaf A, Teng MS, Huang D, Genden EM: Adjuvant radiotherapy and survival for patients with node-positive head and neck cancer: an analysis by primary site and nodal stage. Int J Radiat Oncol Biol Phys 2008, 71:362-370.

3. Vivek RS, Baludavid M, Mohanram R: Concurrent chemo-irradiation using accelerated concomitant boost radiation therapy in loco-regionally advanced head and neck squamous cell carcinomas. J Cancer Res Ther 2006, 2:90-96

4. Bernier J, Domenge C, Ozsahin M, Matuszewska K, Lefèbvre JL, Greiner RH, Giralt J, Maingon P, Rolland F, Bolla M, Cognetti F, Bourhis J, Kirkpatrick A, van Glabbeke M: Postoperative irradiation with or without concomitant chemotherapy for locally advanced head and neck cancer. N Engl J Med 2004, 350:1945-1952.

5. Pignon JP, Bourhis J, Domenge C, Designe L: Chemotherapy added to locoregional treatment for head and neck squamous-cell carcinoma: three meta-analyses of updated individual data. MACH-NC Collaborative Group. Meta-Analysis of Chemotherapy on Head and Neck Cancer. Lancet 2000, 355:949-955.

6. Dassonville O, Formento JL, Francoual M, Ramaioli A, Santini J, Schneider M, Demard F, Milano G: Expression of epidermal growth factor receptor and survival in upper aerodigestive tract cancer. J Clin Oncol 1993, 11:1873-1878.

7. Grandis JR, Tweardy DJ: Elevated levels of transforming growth factor alpha and epidermal growth factor receptor messenger RNA are early markers of carcinogenesis in head and neck cancer. Cancer Res 1993, 53:3579-3584.

8. Ang KK, Berkey BA, Tu X, Zhang HZ, Katz R, Hammond EH, Fu KK, Milas L: Impact of epidermal growth factor receptor expression on survival and pattern of relapse in patients with advanced head and neck carcinoma. Cancer Res 2002, 62:7350-7356.

9. Pectasides E, Rampias T, Kountourakis P, Sasaki C, Kowalski D, Fountzilas G Zaramboukas T, Rimm D, Burtness B, Psyrri A: Comparative Prognostic Value of EGFR Protein Expression Compared with FISH for Head and Neck Squamous Cell Carcinoma (HNSCC). Clin Cancer Res 2011.

10. Mendelsohn J, Baselga J: Status of epidermal growth factor receptor antagonists in the biology and treatment of cancer. J Clin Oncol 2003, 21:2787-2799

11. Greenhalgh J, Bagust A, Boland A, Fleeman N, McLeod C, Dundar Y, Proudlove C, Shaw R: Cetuximab for the treatment of recurrent and/or metastatic squamous cell carcinoma of the head and neck. Health Technol Assess 2009, 13(Suppl 3):49-54.

12. Wild-Bode C, Weller M, Rimner A, Dichgans J, Wick W: Sublethal irradiation promotes migration and invasiveness of glioma cells: implications for radiotherapy of human glioblastoma. Cancer Res 2001, 61:2744-2750.

13. Chung CH, Ely K, McGavran L, Varella-Garcia M, Parker J, Parker N, Jarrett C, Carter J, Murphy BA, Netterville J, Burkey BB, Sinard R, Cmelak A, Levy S, Yarbrough WG, Slebos RJ, Hirsch FR: Increased epidermal growth factor receptor gene copy number is associated with poor prognosis in head and neck squamous cell carcinomas. Journal of Clinical Oncology 2006, 24:4170-4176.

14. Dent P, Yacoub A, Contessa J, Caron R, Amorino G, Valerie K, Hagan MP, Grant S, Schmidt-Ullrich R: Stress and radiation-induced activation of multiple intracellular signaling pathways. Radiat Res 2003, 159:283-300.

15. Cassell A, Grandis JR: Investigational EGFR-targeted therapy in head and neck squamous cell carcinoma. Expert Opin Investig Drugs 2010, 19:709-722.

16. Bonner JA, Harari PM, Giralt J, Cohen RB, Jones CU, Sur RK, Raben D, Baselga J, Spencer SA, Zhu J, Youssoufian H, Rowinsky EK, Ang KK Radiotherapy plus cetuximab for locoregionally advanced head and neck cancer: 5-year survival data from a phase 3 randomised trial, and relation between cetuximab-induced rash and survival. Lancet Oncol 2010, 11:21-28

17. Reiter R, Gais P, Steuer-Vogt MK, Boulesteix AL, Deutschle T, Hampel R, Wagenpfeil S, Rauser S, Walch A, Bink K, Jutting U, Neff F, Arnold W, Hofler H, Pickhard A: Centrosome abnormalities in head and neck squamous cell carcinoma (HNSCC). Acta Otolaryngol 2009, 129:205-213.

18. Reiter R, Gais $P$, Jütting U, Steuer-Vogt MK, Pickhard A, Bink K, Rauser $S$, Lassmann S, Höfler H, Werner M, Walch A: Aurora kinase A messenger
RNA overexpression is correlated with tumor progression and shortened survival in head and neck squamous cell carcinoma. Clin Cancer Res 2006, 12:5136-5141.

19. Corvo R, Antognoni P, Sanguineti G: Biological predictors of response to radiotherapy in head and neck cancer: recent advances and emerging perspectives. Tumori 2001, 87:355-363.

20. Torre C, Wang SJ, Xia W, Bourguignon LY: Reduction of hyaluronan-CD44mediated growth, migration, and cisplatin resistance in head and neck cancer due to inhibition of Rho kinase and Pl-3 kinase signaling. Arch Otolaryngol Head Neck Surg 2010, 136:493-501.

21. Clark C, Shah S, Herman-Ferdinandez L, Ekshyyan O, Abreo F, Rong X, McLarty J, Lurie A, Milligan EJ, Nathan CO: Teasing out the best molecular marker in the AKT/mTOR pathway in head and neck squamous cell cancer patients. Laryngoscope 2010, 120:1159-1165.

22. Testa JR, Bellacosa A: AKT plays a central role in tumorigenesis. Proc Natl Acad Sci USA 2001, 98:10983-10985.

23. Neiva KG, Zhang Z, Miyazawa M, Warner KA, Karl E, Nör JE: Cross talk initiated by endothelial cells enhances migration and inhibits anoikis of squamous cell carcinoma cells through STAT3/Akt/ERK signaling. Neoplasia 2009, 11(6):583-93.

24. Tamura M, Gu J, Matsumoto K, Aota S, Parsons R, Yamada KM: Inhibition of cell migration, spreading, and focal adhesions by tumor suppressor PTEN. Science 1998, 280:1614-1617.

25. Bito T, Sumita N, Ashida M, Budiyanto A, Ueda M, Ichihashi M, Tokura Y, Nishigori C: Inhibition of Epidermal Growth Factor Receptor and PI3K/Akt Signaling Suppresses Cell Proliferation and Survival through Regulation of Stat3 Activation in Human Cutaneous Squamous Cell Carcinoma. J Skin Cancer 2011, 2011:874571, Epub 2010 Dec 8.

26. Kawamata H, Nakashiro K, Uchida D, Harada K, Yoshida H, Sato M: Possible contribution of active MMP2 to lymph-node metastasis and secreted cathepsin $\mathrm{L}$ to bone invasion of newly established human oralsquamous-cancer cell lines. Int J Cancer 1997, 70:120-127.

27. Gioanni J, Fischel JL, Lambert JC, Demard F, Mazeau C, Zanghellini E, Ettore F, Formento P, Chauvel P, Lalanne CM: Two new human tumor cell lines derived from squamous cell carcinomas of the tongue: establishment, characterization and response to cytotoxic treatment. Eur J Cancer Clin Oncol 1988, 24:1445-1455.

28. Rodriguez LG, Wu X, Guan JL: Wound-healing assay. Methods Mol Biol 2005, 294:23-29

29. Alley MC, Scudiero DA, Monks A, Hursey ML, Czerwinski MJ, Fine DL, Abbott BJ, Mayo JG, Shoemaker RH, Boyd MR: Feasibility of drug screening with panels of human tumor cell lines using a microculture tetrazolium assay. Cancer Res 1988, 48:589-601.

30. Silva P, Homer JJ, Slevin NJ, Musgrove BT, Sloan P, Price P, West CM Clinical and biological factors affecting response to radiotherapy in patients with head and neck cancer: a review. Clinical Otolaryngology 2007, 32:337-345.

31. Bernier J, Bentzen SM: Altered fractionation and combined radiochemotherapy approaches: pioneering new opportunities in head and neck oncology. European Journal of Cancer 2003, 39:560-571.

32. Ghadjar P, Simcock M, Studer G, Allal AS, Ozsahin M, Bernier J, Töpfer M, Zimmermann F, Betz M, Glanzmann C, Aebersold DM: Concomitant Cisplatin and Hyperfractionated Radiotherapy in Locally Advanced Head and Neck Cancer: 10-Year Follow-up of a Randomized Phase III Trial (SAKK 10/94). Int J Radiat Oncol Biol Phys 2011.

33. Wick W, Wick A, Schulz JB, Dichgans J, Rodemann HP, Weller M: Prevention of irradiation-induced glioma cell invasion by temozolomide involves caspase 3 activity and cleavage of focal adhesion kinase. Cancer Research 2002 62:1915-1919.

34. Arteaga CL: Epidermal growth factor receptor dependence in human tumors: More than just expression? Oncologist 2002, 7:31-39.

35. Noordhuis MG, Eijsink JJ, Roossink F, de Graeff P, Pras E, Schuuring E, Wisman GB, de Bock GH, van der Zee AG: Prognostic cell biological markers in cervical cancer patients primarily treated with (chemo) radiation: a systematic review. Int J Radiat Oncol Biol Phys 2011 79(2):325-34.

36. Frampton JE: Cetuximab: a review of its use in squamous cell carcinoma of the head and neck. Drugs 2010, 70(15):1987-2010.

37. Meng Q, Xia C, Fang J, Rojanasakul Y, Jiang BH: Role of PI3K and AKT specific isoforms in ovarian cancer cell migration, invasion and 
proliferation through the p70S6K1 pathway. Cellular Signalling 2006,

18:2262-2271

38. Zheng ZZ, Liu ZX: Activation of the phosphatidylinositol 3-kinase/protein kinase Akt pathway mediates CD151-induced endothelial cell proliferation and cell migration. International Journal of Biochemistry \& Cell Biology 2007, 39:340-348.

39. Bussink J, van der Kogel AJ, Kaanders JHAM: Activation of the PI3-K/AKT pathway and implications for radioresistance mechanisms in head and neck cancer. Lancet Oncology 2008, 9:288-296.

40. Zimmermann S, Moelling K: Phosphorylation and regulation of Raf by Akt (protein kinase B). Science 1999, 286:1741-1744.

41. Gupta AK, Cerniglia GJ, Mick R, Ahmed MS, Bakanauskas VJ, Muschel RJ, McKenna WG: Radiation sensitization of human cancer cells in vivo by inhibiting the activity of PI3k using LY294002. International Journal of Radiation Oncology Biology Physics 2003, 56:846-853.

42. Thariat J, Yildirim G, Mason KA, Garden AS, Milas L, Ang KK: Combination of radiotherapy with EGFR antagonists for head and neck carcinoma. International Journal of Clinical Oncology 2007, 12:99-110.

\section{Pre-publication history}

The pre-publication history for this paper can be accessed here: http://www.biomedcentral.com/1471-2407/11/388/prepub

doi:10.1186/1471-2407-11-388

Cite this article as: Pickhard et al:: Inhibition of radiation induced migration of human head and neck squamous cell carcinoma cells by blocking of EGF receptor pathways. BMC Cancer 2011 11:388.

\section{Submit your next manuscript to BioMed Central and take full advantage of:}

- Convenient online submission

- Thorough peer review

- No space constraints or color figure charges

- Immediate publication on acceptance

- Inclusion in PubMed, CAS, Scopus and Google Scholar

- Research which is freely available for redistribution

Submit your manuscript at www.biomedcentral.com/submit 